\title{
MiR-132-3p suppresses cell proliferation and migration in gastric cancer by targeting KIF21B/Wnt/ $\beta$-catenin signaling pathway
}

Bingtian Liu

Ling Qiang

Bingxin Guan

Zhipeng Ji ( $\nabla$ jizhi_peng0304@126.com )

\section{Research Article}

Keywords: Gastric cancer, KIF21B, miR-132-3p, Wnt/ $\beta$-catenin signaling, EMT

Posted Date: October 18th, 2021

DOI: https://doi.org/10.21203/rs.3.rs-956317/v1

License: (c) (1) This work is licensed under a Creative Commons Attribution 4.0 International License. Read Full License 


\section{Abstract}

Background: Recently, kinesin family member 21B (KIF21B) has been reported to be an oncogene in nonsmall cell lung cancer and hepatocellular carcinoma. However, the functional role and related molecular mechanisms underlying gastric cancer (GC) pathogenesis remain largely uncovered.

Methods: The expression of KIF21B was investigated by analysis of Oncomine microarray gene expression datasets and clinical specimens. The association between KIF21B and miR-132-3p was assessed by luciferase reporter assay. CCK-8 assay and transwell assay were performed to analyze the functional role of miR-132-3p/KIF21B in GC cells. Related protein expression levels were evaluated by immunohistochemistry and western blot analysis.

Results: We first found that the expression of KIF21B was upregulated in GC tissues compared with adjunct normal tissues. Knockdown of KIF21B significantly suppressed the proliferation, migration and invasion in GC cell lines (AGS and SNU-5). KIF21B was confirmed as the target of miR-132-3p in GC cells. Moreover, miR-132-3p was down-regulated and inversely correlated with KIF21B expression in GC tissues. Further functional experiments demonstrated that overexpression of KIF21B remarkedly reversed the suppressive effects of miR-132-3p overexpression on GC cell proliferation, migration and invasion. Furthermore, miR-132-3p overexpression downregulated the protein levels of Wnt1, c-Myc, $\beta$-catenin, PCNA and N-cadherin, and upregulated E-cadherin expression in GC cells, which were all alleviated after KIF21B overexpression.

Conclusions: In summary, our findings provide the first evidence that down-regulation of KIF21B by miR132-3p suppresses cellular functions in GC via regulating Wnt/ $\beta$-catenin signaling.

\section{Background}

Gastric cancer (GC) is considered as the third leading cause of tumor-associated death worldwide, remaining a global health problem $(1,2)$. Despite advances in comprehensive therapies, including surgery, adjuvant chemotherapy and radiation interventions, the prognosis of GC patients remains poor primarily ascribed to the diagnosis of GC at an advanced stage and uncontrolled metastasis $(3,4)$. Therefore, having a better understanding the molecular mechanisms associated with GC pathogenesis will be great importance to improve the clinical outcomes of GC patients.

Kinesin superfamily proteins (KIFs), as microtubule-dependent molecular motors, perform a series of cellular processes, including mitosis, motility and organelle transportation (5-7). KIFs have been recently found to be aberrantly expressed and participated in tumorigenesis by modulating chromosomal and spindle movement (8-10). As a member of the KIFs, kinesin family member 21B (KIF21B), located at 1q32.1, contains a motor domain, a stalk and a tail domain binding to microtubules, which is essential for neuronal morphology (11). Interestingly, accumulating evidence has demonstrated that KIF21B was involved in several diseases, especially tumorigenesis. For instance, increased KIF21B expression is correlated with severe multiple sclerosis and Alzheimer's disease pathology $(12,13)$. The influence of 
KIF21B may be relevant to mechanism underlying autism spectrum disorders etiology (14). Zhao et al (15) showed that KIF21B expression level was associated with overall survival and disease-free survival in hepatocellular carcinoma. Sun et al (16) not only manifested that increased KIF21B expression was correlated with worse survival prognosis, and uncontrolled cell proliferation and migration in nonsmall cell lung cancer (NSCLC). However, little is known about the functional role of KIF21B in GC.

MicroRNAs (miRNAs/miRs), a class of small non-coding RNAs, have been frequently demonstrated to function as pivotal regulators in tumorigenesis though modulating various biological processes, including proliferation, invasion and differentiation via binding to the 3 ' untranslated region (3'-UTR) of target genes (17-20). In recent years, miR-132-3p has been reported to be aberrantly expressed in tumor tissues and serve an important regulator in tumor cell functions. For example, miR-132-3p suppressed breast carcinoma cell migration and invasion by targeting lysosomal-associated protein transmembrane 4 beta (LAPTM4B) (21). Ectopic miR-132-3p aggravated cell apoptosis and inhibited cell proliferation in mantle cell lymphoma (22). In addition, miR-132-3p functions as a tumor suppressor in colorectal cancer $(23,24)$, osteosarcoma $(25,26)$ and bladder carcinoma $(27)$. Here, our previous investigation revealed that KIF21B was a potential target gene of miR-132-3p. Moreover, Zhang et al (28) and Wang et al (29) consistently demonstrated that miR-132-3p expression was significantly altered between tumor tissues and normal tissues derived from patients with GC by microRNA profiling. Based on these facts, we speculated that miR-132-3p/KIF21B axis plays a critical role in regulating cell functions in GC cells.

To validate our hypothesis, we first determined the expression pattern of KIF21B in GC tissues by searching Oncomine database and collecting clinical specimens. Then, loss-of-function assays were performed to analyze the functional role of KIF21B in GC cells. Furthermore, we further explored whether KIF21B was the downstream regulator involved in miR-132-3p regulating GC cell functions by modulating Wnt/ $\beta$-catenin signaling. Our findings may provide novel insights into the treatment of GC.

\section{Materials And Methods}

\section{Oncomine gene expression analysis}

We first examined the expression of KIF21B gene in GC by searching microarray gene expression datasets derived from Oncomine database (www.oncomine.com). In brief, the Cancer Type was defined as Gastric Cancer, Data Type was mRNA, and Analysis Type was Cancer versus Normal Analysis. Total three datasets, including Wang Gastric (30), Chen Gastric (31) and DErrico Gastric (32) were included in our analysis. The log-transformed, median-centered and normalized expression values of KIF21B were extracted, analyzed and read from the scatterplot accordingly.

\section{Tissue specimens}

Total thirty pairs of fresh tumor tissues and matched adjacent normal stomach mucosa tissues were collected from GC patients who received radical gastrectomy at the Second Hospital, Cheeloo College of 
Medicine, Shandong University (Shandong Province, China). All patients did not receive radiotherapy and chemotherapy before surgery. In addition, paraffin-embedded specimens of GC were also obtained to evaluate the KIF21B protein expression. Informed consent was obtained from all patients. This study was conducted in accordance with Helsinki Declaration and approved by the Medical Ethics Committee of the Second Hospital, Cheeloo College of Medicine, Shandong University (Approval number: CCM32-J2; 2018.6.3; Shandong, China).

\section{Immunohistochemistry}

Immunohistochemistry staining was performed to assess the protein expression of KIF21B in tissue samples using the EliVisionTMplus kit (Maixin, Fuzhou, China) according to the instructions provided. Briefly, paraffin-embedded tissues were sliced into 5- $\mu \mathrm{m}$ thick sections. The tissue sections were deparaffinized in xylene and rehydrated in gradient ethanol. After subjected to antigen retrieval by heated citrate buffer, sections were blocked in $3 \%(\mathrm{v} / \mathrm{v})$ hydrogen peroxide for $30 \mathrm{~min}$ and incubated overnight at $4{ }^{\circ} \mathrm{C}$ with anti-KIF21B antibody (ab121931; Abcam, Cambridge, UK). Afterwards, the sections were washed with twice with Tris-buffered saline and then incubated with horseradish peroxidase-conjugated secondary antibody for $2 \mathrm{~h}$ at room temperature. The immunohistochemistry staining results were evaluated by two independent pathologists according to the multiplication of staining proportion score (0-4: $0,0-5 \% ; 1,6-20 \% ; 2,21-60 \% ; 3,61-75 \%$; or $4,76-100 \%)$ and staining intensity score $(0$, no staining; 1 , weak; 2 , moderate; 3 , strong staining) as the final score of KIF21B protein expression. Tissue sections with immunoreactivity score scaling $0-2,2-4$ and over 4 were considered to be weak staining (-+), moderate staining $(+)$ and strong staining $(++)$, respectively.

\section{Cell culture and transfection}

Two GC cell lines, including AGS and SNU-5 were purchased from the Cell Bank of China Academy of Sciences (Shanghai, China) and cultured RPMI-1640 medium (Thermo Fisher Scientific, Inc., Waltham, MA, USA) supplemented with $10 \%$ fetal bovine serum (FBS, Gibco) at $37^{\circ} \mathrm{C}$ in the atmosphere containing $5 \% \mathrm{CO}_{2}$. The sequences of small interfering RNA targeting KIF21B (si-KIF21B\#1 and si-KIF21B\#2), si-NC, miR-132-3p mimics and miR-NC were synthesized by GenePharma Co., Ltd. (Shanghai, China). The pcDNA3.1 containing the open reading frame of KIF21B or empty vector were purchased from GenScript (Nanjing, China). After incubating GC cells in 12-well plates at a density of $8 \times 10^{4}$ cells per well, the cells were transfected with the above oligonucleotides for $48 \mathrm{~h}$ using Lipofectamine 2000 (Thermo Fisher Scientific, Inc.).

\section{Reverse transcription quantitative PCR analysis}

Total RNA sample was extracted from tissue specimens or cell lines using TRIzol reagent (Invitrogen). Reverse transcription was conducted by One Step PrimeScript miRNA complementary DNA Synthesis Kit (Takara, Dalian, China) for miR-132-3p and a HiFiScript cDNA Synthesis Kit (CWBIO, Beijing, China) for KIF21B. Next, reverse transcription quantitative PCR was performed to determine the expression of miR132-3p and KIF21B using SYBR Green Human miRNA Assay Kit and a SYBR Premix Ex Taq II kit (Takara, 
Japan), respectively. The primer sequences were used as follows: miR-132-3p (forward: 5》-

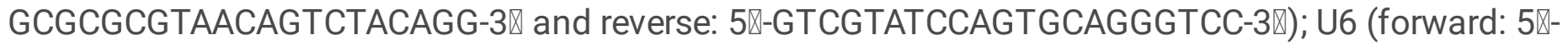
CTCGCTTCGGCAGCACATATACT-3® and reverse: 5囚-CGCTTCACGAATTTGCGTGT-3囚); KIF21B (forward: 5'CGA GGAGACGGATGAGAACG-3' and reverse, 5'-CCACCAGGCTCTCTTCACTG-3'); $\beta$-actin (forward: 5'CCCGAGCCGTGTTTCCT-3' and reverse: 5'-GTCCCAGTTGGT GACGATGC-3'). Relative miR-132-3p and

KIF21B mRNA expression were normalized against the endogenous control U6 and $\beta$-actin, respectively using the $2-\Delta \Delta \mathrm{Ct}$ method (33).

\section{Cell counting kit-8 (CCK-8) assay}

Transfected cells at a density of $4 \times 10^{3}$ cells per well were seeded into 96 -well plates and cultured at 37 ${ }^{\circ} \mathrm{C}$. At $0,24,48$ and $72 \mathrm{~h}$, respectively, cells in each well were incubated with $10 \mu \mathrm{l}$ of CCK-8 solution (Solarbio Science \& Technology, Beijing, China) for another $2 \mathrm{~h}$ at $37^{\circ} \mathrm{C}$. Afterwards, the optical density (OD) value at $450 \mathrm{~nm}$ was measured with a microplate reader.

\section{Transwell migration and invasion assay}

For migration assay, approximately $4 \times 10^{4}$ transfected cells in $200 \mu \mathrm{l}$ of serum-free medium were plated into the upper chamber (24-well insert; 8- $\mu$ m pore size; Corning Costar, Corning, NY, USA), while $600 \mu \mathrm{l}$ complete medium (with 10\% FBS) as chemoattractant was added into the lower chamber. After $24 \mathrm{~h}$ incubation, the cells that migrated to the lower chamber were fixed with $4 \%$ paraformaldehyde for $30 \mathrm{~min}$ and stained with $0.1 \%$ crystal violet for $10 \mathrm{~min}$. The number of migrated cells was quantified under a microscope (magnification, $\times 100$ ) in five random microscope fields. The procedure of invasion assay was similar to the migration assay except for the addition of $50 \mu$ l Matrigel on the membranes of transwell inserts and incubation time of $48 \mathrm{~h}$.

\section{Bioinformatic analysis and luciferase reporter assay}

The potential miRNAs that target KIF21B were predicted by TargetScan (www.targetscan.org/vert_71/). From all these predictions, we selected miR-132-3p for further analysis. The mRNA 3'-UTR of KIF21B, carrying the predicted binding site or mutant binding site of miR-132-3p, was amplified by PCR and cloned into pmirGLO (Promega, Madison, Wisconsin), which were named as KIF21B wild-type (WT) and mutant (MUT) constructs, respectively. Next, cells were co-transfected with KIF21B WT or KIF21B MUT and miR-132-3p mimics or miR-NC using the transfection reagent Lipofectamine 2000. After $48 \mathrm{~h}$ incubation, cells were harvested and relative luciferase activity was measured via a Dual-luciferase reporter assay system (Promega).

\section{Western blot analysis}

Total protein sample was extracted with RIPA lysis buffer with protease inhibitor (Solarbio Science \& Technology Co., Ltd., Beijing, China) and protein concentration was determined by a BCA kit (Beyotime, Shanghai, China). Then, equal amount of protein sample was separated by $10 \%$ SDS-PAGE and 
transferred onto PVDF membranes (Millipore, Billerica, MA, USA). After blocked with $5 \%$ non-fat milk, the membranes were incubated with primary antibodies against KIF21B, Wnt1, c-Myc, $\beta$-catenin, PCNA, Ecadherin, N-cadherin and GAPDH (All from Abcam, Cambridge, UK) at $4{ }^{\circ} \mathrm{C}$ overnight. Subsequently, the membranes were incubated with horseradish peroxidase-coupled secondary antibody for $2 \mathrm{~h}$ at room temperature, followed by detection of protein signals with an enhanced chemiluminescence reagent (EMD Millipore, Billerica, MA, USA).

\section{Statistical analysis}

All quantitative data were presented as mean \pm SD from three independent experiments. All statistical analyses were performed using GraphPad Prism 6.0 (GraphPad Software, Inc., San Diego, California, USA). Differences between two groups were assessed by paired Student's t-test. Differences among three groups were evaluated by one-way analysis of variance (ANOVA), followed by Dunnett's test or Tukey's test. The correlation between miR-132-3p and KIF21B was evaluated using Pearson's correlation coefficient analysis. The $p$-value less than 0.05 was considered to be statistically significant.

\section{Results}

\section{KIF21B expression level was upregulated in GC tissues}

Oncomine microarray gene expression datasets were first searched to investigate the expression pattern of KIF21B in GC. As depicted in Figure 1A, KIF21B expression level was significantly increased in gastric cancer tissues ( $p=7.73 \mathrm{E}-4)$ compared with the corresponding normal tissues in the Wang Gastric dataset, in diffuse gastric adenocarcinoma $(p=0.002)$ and gastric intestinal type adenocarcinoma ( $p=$ $0.005)$ compared with normal tissues in Chen Gastric dataset, as well as in gastric intestinal type adenocarcinoma $(p=0.010)$ and gastric mixed adenocarcinoma $(p=0.016)$ compared with normal tissues in DErrico Gastric dataset. To confirm the upregulation of KIF21B in GC, reverse transcription quantitative PCR was performed to analyze the expression of KIF21B mRNA in thirty pairs of fresh GC tissue and matched adjacent normal tissues. As shown in Figure 1B, the expression of KIF21B mRNA was significantly upregulated in GC tissues compared to that in adjacent tissues. Moreover, we observed the representative photomicrographs of different degrees of KIF21B expression intensity in the cytoplasm by $\mathrm{IHC}$ analysis (Figure 1C).

\section{Knockdown of KIF21B inhibited the proliferation, migration and invasion of GC cells}

Next, we explored the functional role of KIF21B in GC cells by performing loss-of-function assays in AGS and SNU-5 cells. At first, the expression of KIF21B protein was suppressed by transfecting with two different siRNAs in AGS and SNU-5 cells, as demonstrated by western blot analysis (Figure 2A). CCK8 assay showed that either si-KIF21B\#1 or si-KIF21B\#2 transfection significantly suppressed cell proliferation ability in AGS and SNU-5 cells (Figure 2A). Notably, si-KIF21B\#2 generated more powerful suppressive effects on KIF21B expression and cell proliferation ability, in comparison with si-KIF21B\#1, which was thus selected for the subsequent in vitro experiments. Subsequently, transwell assay was 
applied to analyze the effects of KIF21B knockdown on GC cell migration and invasion. Our data showed that the number of migratory cells was remarkedly decreased in si-KIF21B\#2 group compared with si-NC group in both AGS and SNU-5 cells (Figure 2C). Similarly, knockdown of KIF21B by si-KIF21B\#2 transfection significantly reduced the number of invasive cells in AGS and SNU-5 cells (Figure 2D).

\section{KIF21B as a target gene of miR-132-3p}

TargetScan 7.1 database was used to predict miRNAs that target KIF21B expression, which led to the identification of miR-132-3p as a direct target gene. As depicted in Figure 3A, miR-132-3p exhibited identical seed regions, with complementary binding to the 3 '-UTR of KIF21B. Then, results from luciferase reporter assay showed that miR-132-3p mimics significantly suppressed the luciferase activity of AGS (Figure 3B) and SNU-5 (Figure 3C) cells transfected with KIF21B WT plasmid. However, the luciferase activity remained unchanged when the cells were transfected with KIF21B MUT without the miR-132-3p binding sites. What's more, miR-132-3p overexpression significantly downregulated KIF21B mRNA (Figure 3D) and protein (Figure 3E) expression levels in both AGS and SNU-5 cells. These findings suggested that miR-132-3p could negatively regulate KIF21B expression through its 3'-UTR. In addition, we analyzed the expression of miR-132-3p in GC tissues. As shown in Figure 3F, miR-132-3p expression level was significantly down-regulated in GC tissues compared to that in adjacent tissues. Furthermore, miR-132-3p expression level was inversely correlated with KIF21B expression level in 30 cases of GC tissues (Figure 3G, $r=-0.4132, p=0.0232$ ).

\section{KIF21B overexpression reversed the suppressive effects of miR-132-3p on GC cells}

Since miR-132-3p was identified to target KIF21B and negative correlated with KIF21B expression in GC tissues, we thus explored whether miR-132-3p regulated GC cell functions by targeting KIF21B. At first, the expression of miR-132-3p was overexpressed in AGS and SNU-5 cells after transfection with miR132-3p mimics, as demonstrated by reverse transcription quantitative PCR (Figure 4A). Then, AGS and SNU-5 cells were co-transfected with miR-132-3p mimics and KIF21B. As shown in Figure 4B, downregulated KIF21B protein level induced by miR-132-3p overexpression was attenuated after KIF21B overexpression plasmid transfection in both AGS and SNU-5 cells. Furthermore, ectopic KIF21B expression effectively reversed miR-132-3p overexpression-mediated suppressive effects on cell proliferation (Figure 4C), migration (Figure 4D) and invasion (Figure 4E) abilities in AGS and SNU-5 cells.

\section{MiR-132-3p suppressed the Wnt/ $\beta$-catenin signaling pathway in GC cells via repressing KIF21B}

It has been reported that $\mathrm{Wnt} / \beta$-catenin signaling pathway participates in regulating tumor cell proliferation and migration. Then, we investigated whether Wnt/ $\beta$-catenin signaling pathway was involved in miR-132-5p-mediated suppressive effects on GC cells. As shown in Figure 5A, miR-132-3p overexpression obviously suppressed the expression of Wnt1, c-Myc and $\beta$-catenin, which was reversed after KIF21B overexpression in AGS cells. In addition, we found that miR-132-3p overexpression downregulated the expression of PCNA and N-cadherin, and upregulated E-cadherin expression in AGS cells, which was reversed after co-transfection with miR-132-3p mimics and KIF21B. Similarly, we 
observed that KIF21B overexpression abolished the effects of miR-132-3p overexpression on the protein levels of Wnt1, c-Myc, $\beta$-catenin, PCNA, E-cadherin and N-cadherin in SNU-5 cells (Figure 5B).

\section{Discussion}

In the current study, we first observed that KIF21B expression was upregulated in GC tissues compared with adjacent normal tissues by analysis of the Oncomine microarray gene expression datasets and clinical specimens. Next, we performed loss-of-function experiments to demonstrate that silencing of KIF21B suppressed the proliferation, migration and invasion of AGS and SNU- 5 cells. Actually, KIFs play crucial roles in mitotic cell division, which make them involved in tumorigenesis $(34,35)$. Similarly, upregulation of KIF14 could promote cancer metastasis in gastric cancer (36) and promote cell proliferation in colorectal cancer (37). KIF11 knockdown significantly inhibited proliferation, migration and invasion in breast cancer (38). Knockdown of KIF23 resulted in a marked inhibition of cell proliferation of GC in mice, with significant downregulation of Ki67 and PCNA expression (39). Consistent with our data, KIF21B was upregulated in hepatocellular carcinoma and NSCLC tissues, which promoted the corresponding tumor cell proliferation, migration and invasion $(15,16)$. Herein, our data highlight the oncogenic role of KIF21B in GC.

We further demonstrated that KIF21B was a potential target of miR-132-3p in AGS and SNU-5 cells. What's more, decreased miR-132-3p expression was found to be inversely correlated with KIF21B mRNA levels in 30 cases of GC tissues. The rescue experiments manifested that KIF21B overexpression significantly alleviated the suppressive effects of miR-132-3p on GC cell proliferation, migration and invasion. These data suggested that miR-132-3p inhibited the cellular functions by directly targeting KIF21B in GC cells. In fact, miR-132-3p expression was demonstrated to be more frequently downregulated in human cancer, including colorectal cancer (40), pancreatic carcinoma (41) and glioma $(42,43)$. Functionally, the suppressive effects of miR-132-3p have been reported on cell proliferation, migration and invasion in breast cancer (21), mantle cell lymphoma (22), colorectal cancer $(23,24)$, osteosarcoma $(25,26)$ and bladder carcinoma $(27)$. Notably, He et al showed that inhibition of miR-132-3p enhanced GC cell proliferation and migration by targeting mucin 13 (MUC13) (44). Despite the suppressive role of miR-132-3p has been reported already, there are some major differences between it and our study as follows: 1) We performed gain-of-function assay to investigate the functional role of miR-132-3p, rather than loss-of-function assay in the above study from He et al. 2) Different target genes of miR-132-3p were identified. 3) Different molecular mechanisms underlying miR-132-3p regulating GC cell functions. 4) In addition to migration and invasion, we analyzed cell proliferation here. Until now, several KIFs have been reported to be directly regulated by miRNAs involved in the development of tumors. For instance, miR-338-3p could directly bind to the 3 '-untranslated region (3'-UTR) of KIFC1 in renal cell carcinoma cells (45). MiR-30a could specifically suppress KIF11 by targeting its 3'-UTR in breast cancer (46). Additionally, miR-206 inhibited the cell proliferation, migration, and invasion of ovarian cancer cells by directly targeting KIF2A (47). To our best knowledge, KIF21B has not been demonstrated to be a target of certain miRNA, which made the identification of KIF21B as the target of miR-132-3p provided a novel therapeutic target against the progression of GC. 
Wnt/ $\beta$-catenin signaling pathway has been widely reported to be frequently over-activated in multiple types of tumors, which plays a fundamental role in regulation of cellular proliferation and invasion (48). What's more, Wnt/ $\beta$-catenin pathway plays a critical role in metastasis and is closely associated with EMT process (49). Here, we found that miR-132-3p overexpression inhibited the activity of Wnt1, c-Myc and $\beta$-catenin, as key effector of Wnt/ $\beta$-catenin signaling pathway and inactivated EMT markers (Ecadherin and N-cadherin), which were all reversed after KIF21B overexpression in GC cells. Similar with our data, miR-132-3p suppressed the migration and invasion of tumor cells by regulating the EMTcorrelated molecules in lung cancer $(50,51)$ and cervical cancer $(52)$. It has been confirmed that KIF26B regulates cell invasion in breast cancer through driving epithelial-mesenchymal transition (EMT) (53). KIF11 knockdown significantly upregulated E-cadherin expression, and downregulated the expression of $\mathrm{N}$-cadherin and Vimentin in breast cancer cells (38). Although the association between miR-132$3 p / K I F 21 B$ and Wnt/ $\beta$-catenin pathway has not been reported yet, we thus speculated miR-132-3p suppressed GC cell proliferation, migration and invasion by targeting KIF21B-mediated Wnt/ $\beta$-catenin pathway based on the correlation of EMT process and Wnt/ $\beta$-catenin pathway.

\section{Conclusions}

In summary, we first demonstrated that KIF21B knockdown suppressed the proliferation, migration and invasion in GC cells. Moreover, we confirmed that KIF21B was the downstream regulator underlying miR$132-3 p$ exerted suppressive effects on GC cells by downregulating Wnt/ $\beta$-catenin pathway. Thus, we findings help us better understand targeting miR-132-3p/KIF21B axis as a promising therapeutic target for GC treatment.

\section{Declarations}

\section{Ethics approval and consent to participate}

The present study was conducted in accordance with Helsinki Declaration and approved by the Ethics Committee of the Second Hospital, Cheeloo College of Medicine, Shandong University (Approval number: CCM32-J2; 2018.6.3; Shandong, China).

\section{Authors' contributions}

Supervision: Zhipeng Li; Interpretation of analysis of data: Bingtian Liu and Ling Qiang; Preparation of the manuscript: Bingxin Guan; Revision for important intellectual content: Ling Qiang. All authors read and approved the final manuscript.

\section{Availability of data and materials}

All results and data generated or analyzed during the present study are included in this published article or are available from the corresponding author on reasonable request. 
Acknowledgements

Not applicable.

\section{Funding}

No funding was received.

\section{Consent for publication}

We have obtained consents to publish this paper from all the participants of this study.

\section{Competing interests}

The authors declare that they have no competing interests.

\section{Abbreviations}

GC: gastric cancer; KIF21B, kinesin family member 21B; GC, gastric cancer; 3'-UTR, 3' untranslated region; LAPTM4B, lysosomal-associated protein transmembrane 4 beta; FBS, fetal bovine serum; CCK-8, Cell counting kit-8; OD, optical density; WT, wild-type; EMT, epithelial-mesenchymal transition

\section{References}

1. Bozkurt O, Firat ST, Dogan E, Cosar R, Inanc M, Ozkan M. The prognostic value of the change in neutrophil-to-lymphocyte ratio during first-line palliative chemotherapy in patients with metastatic gastric cancer: A retrospective study. Journal of BUON : official journal of the Balkan Union of Oncology. 2019 Sep-Oct;24(5):1992-9. PubMed PMID: 31786866.

2. Sitarz R, Skierucha M, Mielko J, Offerhaus GJA, Maciejewski R, Polkowski WP. Gastric cancer: epidemiology, prevention, classification, and treatment. Cancer management and research. 2018;10:23948. PubMed PMID: 29445300. Pubmed Central PMCID: 5808709.

3. Baba H, Kuwabara K, Ishiguro T, Kumamoto K, Kumagai $\mathrm{Y}$, Ishibashi K, et al. Prognostic factors for stage IV gastric cancer. International surgery. 2013 Apr-Jun;98(2):181-7. PubMed PMID: 23701157. Pubmed Central PMCID: 3723175.

4. Zhou Q, Lan X, Li N, Yuan D, Zhang J. Analysis of Prognostic Factors and Design of Prognosis Model for Patients with Stage IV Gastric Cancer Following First-Line Palliative Chemotherapy. Cancer management and research. 2020;12:10461-8. PubMed PMID: 33122945. Pubmed Central PMCID: 7588669.

5. Hirokawa N, Tanaka Y. Kinesin superfamily proteins (KIFs): Various functions and their relevance for important phenomena in life and diseases. Experimental cell research. 2015 May 
15;334(1):16-25. PubMed PMID: 25724902.

6. Hirokawa N, Noda Y. Intracellular transport and kinesin superfamily proteins, KIFs: structure, function, and dynamics. Physiological reviews. 2008 Jul;88(3):1089-118. PubMed PMID: 18626067.

7. Hirokawa N, Noda Y, Tanaka Y, Niwa S. Kinesin superfamily motor proteins and intracellular transport. Nature reviews Molecular cell biology. 2009 Oct;10(10):682-96. PubMed PMID: 19773780.

8. Myers SM, Collins I. Recent findings and future directions for interpolar mitotic kinesin inhibitors in cancer therapy. Future medicinal chemistry. 2016;8(4):463-89. PubMed PMID: 26976726. Pubmed Central PMCID: 4896392.

9. Liu X, Gong H, Huang K. Oncogenic role of kinesin proteins and targeting kinesin therapy. Cancer science. 2013 Jun;104(6):651-6. PubMed PMID: 23438337. Pubmed Central PMCID: 7657121.

10. Liu Y, Zhan P, Zhou Z, Xing Z, Zhu S, Ma C, et al. The overexpression of KIFC1 was associated with the proliferation and prognosis of non-small cell lung cancer. Journal of thoracic disease. 2016 Oct;8(10):2911-23. PubMed PMID: 27867568. Pubmed Central PMCID: 5107536.

11. Muhia M, Thies E, Labonte D, Ghiretti AE, Gromova KV, Xompero F, et al. The Kinesin KIF21B Regulates Microtubule Dynamics and Is Essential for Neuronal Morphology, Synapse Function, and Learning and Memory. Cell reports. 2016 May 3;15(5):968-77. PubMed PMID: 27117409. Pubmed Central PMCID: 5305027.

12. Kreft KL, van Meurs M, Wierenga-Wolf AF, Melief MJ, van Strien ME, Hol EM, et al. Abundant kif21 $\mathrm{b}$ is associated with accelerated progression in neurodegenerative diseases. Acta neuropathologica communications. 2014 Oct 3;2:144. PubMed PMID: 25274010. Pubmed Central PMCID: PMC4207309. Epub 2014/10/03. eng.

13. Hares K, Miners JS, Cook AJ, Rice C, Scolding N, Love S, et al. Overexpression of Kinesin Superfamily Motor Proteins in Alzheimer's Disease. Journal of Alzheimer's disease : JAD. 2017;60(4):1511-24. PubMed PMID: 29060936.

14. Gromova KV, Muhia M, Rothammer N, Gee CE, Thies E, Schaefer I, et al. Neurobeachin and the Kinesin KIF21B Are Critical for Endocytic Recycling of NMDA Receptors and Regulate Social Behavior. Cell reports. 2018 May 29;23(9):2705-17. PubMed PMID: 29847800. Epub 2018/05/31. eng.

15. Zhao HQ, Dong BL, Zhang M, Dong XH, He Y, Chen SY, et al. Increased KIF21B expression is a potential prognostic biomarker in hepatocellular carcinoma. World journal of gastrointestinal oncology. 2020 Mar 15;12(3):276-88. PubMed PMID: 32206178. Pubmed Central PMCID: PMC7081114. Epub 2020/03/25. eng.

16. Sun ZG, Pan F, Shao JB, Yan QQ, Lu L, Zhang N. Kinesin superfamily protein 21B acts as an oncogene in non-small cell lung cancer. Cancer cell international. 2020;20:233. PubMed PMID: 32536821. 
Pubmed Central PMCID: PMC7291654. Epub 2020/06/17. eng.

17. Kunej T, Godnic I, Ferdin J, Horvat S, Dovc P, Calin GA. Epigenetic regulation of microRNAs in cancer: an integrated review of literature. Mutation research. 2011 Dec 1;717(1-2):77-84. PubMed PMID: 21420983.

18. Cortez MA, Anfossi S, Ramapriyan R, Menon H, Atalar SC, Aliru M, et al. Role of miRNAs in immune responses and immunotherapy in cancer. Genes, chromosomes \& cancer. 2019 Apr;58(4):244-53. PubMed PMID: 30578699. Pubmed Central PMCID: 6368474.

19. Jia XN, Yin SD, Wei Y, Chen L. MiR-182-5p inhibited proliferation and migration of ovarian cancer cells by targeting BNIP3. European review for medical and pharmacological sciences. 2020 Aug;24(15):7912. PubMed PMID: 32767306.

20. Wang L, Wang Y, Du X, Yao Y, Wang L, Jia Y. MiR-216b suppresses cell proliferation, migration, invasion, and epithelial-mesenchymal transition by regulating FOXM1 expression in human non-small cell lung cancer. OncoTargets and therapy. 2019;12:2999-3009. PubMed PMID: 31114243. Pubmed Central PMCID: 6489682.

21. Li S, Xu JJ, Zhang QY. MicroRNA-132-3p inhibits tumor malignant progression by regulating lysosomal-associated protein transmembrane 4 beta in breast cancer. Cancer science. 2019 Oct;110(10):3098-109. PubMed PMID: 31389121. Pubmed Central PMCID: 6778625.

22. Wu B, Li J, Wang H, Wu Q, Liu H. MiR-132-3p serves as a tumor suppressor in mantle cell lymphoma via directly targeting SOX11. Naunyn-Schmiedeberg's archives of pharmacology. 2020 Nov;393(11):2197-208. PubMed PMID: 32040593. Epub 2020/02/11. eng.

23. He X, Ma J, Zhang M, Cui J, Yang H. Long Non-Coding RNA SNHG16 Activates USP22 Expression to Promote Colorectal Cancer Progression by Sponging miR-132-3p. OncoTargets and therapy. 2020;13:4283-94. PubMed PMID: 32547062. Pubmed Central PMCID: PMC7244243. Epub 2020/06/18. eng.

24. Zhang M, Li Y, Wang H, Yu W, Lin S, Guo J. LncRNA SNHG5 affects cell proliferation, metastasis and migration of colorectal cancer through regulating miR-132-3p/CREB5. Cancer biology \& therapy. 2019;20(4):524-36. PubMed PMID: 30395767. Pubmed Central PMCID: PMC6422517. Epub 2018/11/06. eng.

25. Guan H, Shang G, Cui Y, Liu J, Sun X, Cao W, et al. Long noncoding RNA APTR contributes to osteosarcoma progression through repression of miR-132-3p and upregulation of yes-associated protein 1. Journal of cellular physiology. 2019 Jun;234(6):8998-9007. PubMed PMID: 30317613. Epub 2018/10/15. eng. 
26. Li G, Liu K, Du X. Long Non-Coding RNA TUG1 Promotes Proliferation and Inhibits Apoptosis of Osteosarcoma Cells by Sponging miR-132-3p and Upregulating SOX4 Expression. Yonsei medical journal. 2018 Mar;59(2):226-35. PubMed PMID: 29436190. Pubmed Central PMCID: PMC5823824. Epub 2018/02/13. eng.

27. Liu P, Li X, Guo X, Chen J, Li C, Chen M, et al. Circular RNA DOCK1 promotes bladder carcinoma progression via modulating circDOCK1/hsa-miR-132-3p/Sox5 signalling pathway. Cell proliferation. 2019 Jul;52(4):e12614. PubMed PMID: 30983072. Pubmed Central PMCID: PMC6668968. Epub 2019/04/16. eng.

28. Zhang T, Liu C, Huang S, Ma Y, Fang J, Chen Y. A Downmodulated MicroRNA Profiling in Patients with Gastric Cancer. Gastroenterology research and practice. 2017;2017:1526981. PubMed PMID: 28546810. Pubmed Central PMCID: PMC5436063. Epub 2017/05/27. eng.

29. Wang J, Zhang H, Zhou X, Wang T, Zhang J, Zhu W, et al. Five serum-based miRNAs were identified as potential diagnostic biomarkers in gastric cardia adenocarcinoma. Cancer biomarkers : section A of Disease markers. 2018;23(2):193-203. PubMed PMID: 30198863. Epub 2018/09/11. eng.

30. Wang Q, Wen YG, Li DP, Xia J, Zhou CZ, Yan DW, et al. Upregulated INHBA expression is associated with poor survival in gastric cancer. Medical oncology. 2012;29(1):77-83.

31. Chen X, Leung SY, Yuen ST, Chu KM, Ji J, Li R, et al. Variation in gene expression patterns in human gastric cancers. Mol Biol Cell. 2003 Aug;14(8):3208-15. PubMed PMID: 12925757. Pubmed Central PMCID: PMC181561. Epub 2003/08/20. eng.

32. D'Errico M, de Rinaldis E, Blasi MF, Viti V, Falchetti M, Calcagnile A, et al. Genome-wide expression profile of sporadic gastric cancers with microsatellite instability. European journal of cancer. 2009 Feb;45(3):461-9. PubMed PMID: 19081245.

33. Livak KJ, Schmittgen TD. Analysis of Relative Gene Expression Data using Real-Time Quantitative PCR. Methods. 2002;25(4):402-8.

34. Huszar D, Theoclitou ME, Skolnik J, Herbst R. Kinesin motor proteins as targets for cancer therapy. Cancer \& Metastasis Reviews. 2009;28(1-2):197-208.

35. Lucanus AJ, Yip GW. Kinesin superfamily: roles in breast cancer, patient prognosis and therapeutics. Oncogene. 2018 Feb 15;37(7):833-8. PubMed PMID: 29059174.

36. Yang Z, Li C, Yan C, Li J, Yan M, Liu B, et al. KIF14 promotes tumor progression and metastasis and is an independent predictor of poor prognosis in human gastric cancer. Biochimica et biophysica acta Molecular basis of disease. 2019 Jan;1865(1):181-92. PubMed PMID: 30404039.

37. Wang ZZ, Yang J, Jiang BH, Di JB, Gao P, Peng L, et al. KIF14 promotes cell proliferation via activation of Akt and is directly targeted by miR-200c in colorectal cancer. International journal of 
oncology. 2018 Nov;53(5):1939-52. PubMed PMID: 30226594. Pubmed Central PMCID: 6192758.

38. Zhou J, Chen WR, Yang LC, Wang J, Sun JY, Zhang WW, et al. KIF11 Functions as an Oncogene and Is Associated with Poor Outcomes from Breast Cancer. Cancer research and treatment : official journal of Korean Cancer Association. 2019 Jul;51(3):1207-21. PubMed PMID: 30590004. Pubmed Central PMCID: PMC6639218. Epub 2018/12/28. eng.

39. Li XL, Ji YM, Song R, Li XN, Guo LS. KIF23 Promotes Gastric Cancer by Stimulating Cell Proliferation. Disease markers. 2019;2019:9751923. PubMed PMID: 31007778. Pubmed Central PMCID: PMC6441499. Epub 2019/04/23. eng.

40. Kara M, Yumrutas O, Ozcan O, Celik Ol, Bozgeyik E, Bozgeyik I, et al. Differential expressions of cancer-associated genes and their regulatory miRNAs in colorectal carcinoma. Gene. 2015 Aug 1;567(1):81-6. PubMed PMID: 25925209.

41. Zhang H, Liu A, Feng X, Tian L, Bo W, Wang H, et al. MiR-132 promotes the proliferation, invasion and migration of human pancreatic carcinoma by inhibition of the tumor suppressor gene PTEN. Progress in biophysics and molecular biology. 2019 Nov;148:65-72. PubMed PMID: 28941804.

42. Hangzhou, Wang, Xue-Tao, Li, Chun, Wu, et al. miR-132 can inhibit glioma cells invasion and migration by target MMP16 in vitro. OncoTargets and therapy. 2015 Nov;8:3211-8. PubMed PMID: 26604788

43. Zhou K, Zhang C, Yao H, Zhang X, Zhou Y, Che Y, et al. Knockdown of long non-coding RNA NEAT1 inhibits glioma cell migration and invasion via modulation of SOX2 targeted by miR-132. Molecular cancer. 2018 Jul 27;17(1):105. PubMed PMID: 30053878. Pubmed Central PMCID: 6064054.

44. He L, Qu L, Wei L, Chen Y, Suo J. Reduction of miR-132-3p contributes to gastric cancer proliferation by targeting MUC13. Molecular medicine reports. 2017 May;15(5):3055-61. PubMed PMID: 28339011. Pubmed Central PMCID: PMC5428394. Epub 2017/03/25. eng.

45. Li G, Chong T, Yang J, Li H, Chen H. Kinesin Motor Protein KIFC1 Is a Target Protein of miR-338$3 p$ and Is Associated With Poor Prognosis and Progression of Renal Cell Carcinoma. Oncology research. 2018 Dec 27;27(1):125-37. PubMed PMID: 29562961. Epub 2018/03/23. eng.

46. Wang B, Yu J, Sun Z, Luh F, Lin D, Shen Y, et al. Kinesin family member 11 is a potential therapeutic target and is suppressed by microRNA-30a in breast cancer. Mol Carcinog. 2020 Aug;59(8):908-22. PubMed PMID: 32346924. Pubmed Central PMCID: PMC7384136. Epub 2020/04/30. eng.

47. Sheng $\mathrm{N}, \mathrm{Xu} \mathrm{YZ}$, Xi QH, Jiang HY, Wang CY, Zhang Y, et al. Overexpression of KIF2A is Suppressed by miR-206 and Associated with Poor Prognosis in Ovarian Cancer. Cellular physiology and 
biochemistry : international journal of experimental cellular physiology, biochemistry, and pharmacology. 2018;50(3):810-22. PubMed PMID: 30352438. Epub 2018/10/24. eng.

48. Logan CY, Nusse R. The Wnt signaling pathway in development and disease. Annual review of cell and developmental biology. 2004;20:781-810. PubMed PMID: 15473860.

49. Talbot LJ, Bhattacharya SD, Kuo PC. Epithelial-mesenchymal transition, the tumor microenvironment, and metastatic behavior of epithelial malignancies. International journal of biochemistry and molecular biology. 2012;3(2):117-36. PubMed PMID: 22773954. Pubmed Central PMCID: 3388731.

50. Guo H, Zhang X, Chen Q, Bao Y, Dong C, Wang X. miR-132 suppresses the migration and invasion of lung cancer cells by blocking USP9X-induced epithelial-mesenchymal transition. American journal of translational research. 2018;10(1):224-34. PubMed PMID: 29423007. Pubmed Central PMCID: PMC5801360. Epub 2018/02/10. eng.

51. You J, Li Y, Fang N, Liu B, Zu L, Chang R, et al. MiR-132 suppresses the migration and invasion of lung cancer cells via targeting the EMT regulator ZEB2. PloS one. 2014;9(3):e91827. PubMed PMID: 24626466. Pubmed Central PMCID: PMC3953608. Epub 2014/03/15. eng.

52. Zhao JL, Zhang L, Guo X, Wang JH, Zhou W, Liu M, et al. miR-212/132 downregulates SMAD2 expression to suppress the G1/S phase transition of the cell cycle and the epithelial to mesenchymal transition in cervical cancer cells. IUBMB life. 2015 May;67(5):380-94. PubMed PMID: 25988335. Epub 2015/05/20. eng.

53. Gu S, Liang H, Qi D, Mao L, Mao G, Qian L, et al. Knockdown of KIF26B inhibits breast cancer cell proliferation, migration, and invasion. OncoTargets and therapy. 2018;11:3195-203. PubMed PMID: 29881293. Pubmed Central PMCID: 5985780.

\section{Figures}

\section{Image not available with this version}


Figure 1

This image is not available with this version.

\section{Image not available with this version}

Figure 2

This image is not available with this version.

\section{Image not available with this version}

Figure 3

This image is not available with this version.

Image not available with this version 
Figure 4

This image is not available with this version.

\section{Image not available with this version}

Figure 5

This image is not available with this version. 